\title{
Open source geographical resources analysis support system (GRASS) for landslide hazard assessment
}

\begin{abstract}
Purpose - The primary aim of this research is to investigate the application of open source geographic information system software, geographical resources analysis support system (GRASS) for landslide hazard assessment. Design/methodology/approach - Five parameters affecting landslide occurrence derived from topographical, geological and land use maps of Cameron highland were used for the assessment. Findings - The results showed that about 93 percent of the study area falls under zone II that is of low hazard, with less than 7 percent on zone III with moderate hazard and only less than 1 percent falls under zone IV, which is of high hazard. Research limitations/implications - The accuracy of the landslide hazard map needs to be assessed by cross-correlation with landslide occurrence in the field. Practical implications - The map produced showed the potential application of GRASS as a tool for producing landslide hazard assessment map. Originality/value - The major outcome of this research is the possible use of open source GIS software in the application of landslide hazard assessment. The capability of GRASS in performing such environmental assessment will certainly attract many researchers and organizations with limited budgets, especially in developing countries such as Malaysia.
\end{abstract}

